\title{
Educational Inequality: An Impediment to True Democracy in the United States
}

\author{
Amy Yun-Ping Chen ${ }^{a}$
}

\begin{abstract}
Many people believe that democracy is something that can lead everyone toward a better nation and a free and fair society. In 1954, Brown v. Board of Education fundamentally changed the education system in the United States and was a turning point in the evolution of U.S. democracy that made the beautiful American dream available for each individual. However, six decades later, the debate over educational inequality continues. People are still fighting for their equality and well-being. Along with dramatically influential political, economic, and social factors in the United States, educational inequality destroys the commitment of this democratic nation to offer equal opportunity, care, and social justice to younger members of the community. This paper discusses the current problem of educational inequality as it relates to racial and socioeconomic discrimination in urban schools. The aim of this study is to explore knowledge of inequality in the U.S. school system and to raise social and educational awareness to help American children to have equal chances in education and to achieve future success.
\end{abstract}

Keywords

Democracy, public education, social mobility, racial inequality, socioeconomic inequality

Public education is a constructive mechanism that prepares children for citizenship and educates them to live in a healthy civic society, and to foster a nation with democracy (Hochschild and Scovronick 2003; Gutmann 1999; Labaree 1997). The early framework of the democratic purpose of education was associated with the public good and aimed to promote the formation of moral character in citizens of the United States (J. Goodland, Mantle-Bromley, and S. Goodland 2004; Hochschild and Scovronick 2003; L. Pangle and T. Pangle 2000). Thomas Jefferson claimed:

The goals of public schooling are to give to every citizen the information he needs for the transaction of his own business, to know his rights and exercise with order and justice those he retains, and in general to observe with intelligence and faithfulness all the social relations under which he shall be placed. (as cited in L. Pangle and T. Pangle 2000: 25)

Thomas Jefferson also considered "Education (as) a filter that could be installed within each individual, giving to each the capacity to rule prudently, universal and public education creates an aristocracy to which all can belong” (Barber 1993: 45). The primary notion of U.S. education holds concern for the public good and significantly serves as the foundation of democratic equality (Labaree 1997; Noddings 2013; L.

aSaint Louis University, USA

\section{Correspondent Author:}

Amy Yun-Ping Chen, Fitzgerald Hall, 3500 Lindell Blvd., Suite 130, St. Louis, M0 63103

E-mail: ychen74@slu.edu 
Pangle and T. Pangle 2000). In addition, education has long been seen as a powerful force with the potential to increase opportunity and promote social mobility. The meanings of democratic equality often include citizenship training, equal treatment, and equal access (Biesta 2010; Labaree 1997; Nieto 2005). Equal access for education also lies at the heart of the American dream (Allen and Reich 2013; Hochschild 1996). It not only helps children from less well-off backgrounds to advance their knowledge and skills and to break generational cycles of deprivation, but also it encourages them to reach for economic growth and life success.

In Democracy and Education, John Dewey (1916) indicates that "A democracy is more than a form of government; it is primarily a mode of associated living, of conjoint communicated experience” (Noddings 2013: 12). In other words, democracy and education share a common life and provide a strong rationale for strengthening collaborative and communicative settings for social interaction and transmission of culture. Education helps human beings in developing critical thoughts and protecting society from the dangers of authoritarianism and dictatorship (Allen and Reich 2013; Biesta 2010). Dewey (1916) also advocated for an essential concept that emphasizes the synthesis of democracy and education in promoting a common goal of a better democratic society.

In the contexts of public policy and reform, the term "common" usually implies application of the same or similar treatment with the aim to bring about the greater interest in the public sphere, as well as a process of decision-making that is based on collective opinions (Gutmann 1999; Gutmann 2001; Noddings 2013). The majority wins; the minority loses. Often this results in the exclusion of individual differences and the production of competition. Barber (2001) wrote:

The democratic faith is rooted in the belief that all humans are capable of such excellence and have not just the right but the capacity to become citizens, and we all are potentially susceptible to education for freedom and responsibility. (Barber 2001: 13, 19)

This potential can be achieved when every young person has equal access to free and quality education, which also indicates the goal of recognition of minority populations and representation of their interests.

Democracy and education are inextricably tied with the thoughts and practices of people in American culture and history. An ideal education should provide appropriate methods of instruction and ensure a future for the younger members of our communities. The educational system should incorporate democratic values, such as respect, justice, trust, and self-determination in a community that upholds freedom and equality (Barber 2001; Biesta 2010; Gutmann 1999; Gutmann 2001). Further, public education should become a tool to achieve the ideal form of democracy through conducting appropriate solutions, elucidating the understanding of citizenship, equipping children with cultivated and reasoned commitments, and leading the United States toward a better future. Public education also should be productive and provide more depth at the levels of knowledge and awareness to aid students in boosting their learning and preparing them for the responsibility of being good citizens. The ultimate goal should not simply be equal access to education but equal quality education to all residents of the United States.

\section{RACIAL AND ETHNIC INEQUALITY IN PUBLIC EDUCATION}

During the school year 2009-2010, one in four Black students and nearly one in five Hispanic students still attended high schools where graduating was not the norm (National Center for Education Statistics [NCES] 2013). Furthermore, a study from Harvard's Kennedy School of Government shows that a mere $11 \%$ of Black students and $15 \%$ of Hispanic students were 
well-advanced in math, as opposed to $42 \%$ of Whites and 50\% of Asians (Love 2011). And in reading, only $13 \%$ of Black students and $4 \%$ of Hispanic students were proficient, compared with $40 \%$ of White students and $41 \%$ of Asian students (Love 2011). The data indicate that the racial and ethnic gap in academic achievement represents the significant educational disparities among different populations in the United States. Thus, what are the major factors causing achievement disparities? One of the most important answers is often attributed to race.

Throughout the history of the United States, race has existed as a set of interpretative codes and meanings that operate in the interactions of every aspect of life (Kozol 1991; Kozol 2006; Lipman 2003; Murrell 2008; Nieto 2005; Pollock 2010). In spite of the abolition of slavery, the decision of Brown $\mathrm{v}$. Board of Education in 1954, and the passage of the Civil Rights Act of 1964, racial segregation and inequality continue to affect the quality of education nationwide (Carter and Welner 2013; Kozol 1991; Kozol 2006; Murrell 2008; Ravitch 2010). Racial categorizing is never a finished product; instead, it functions as a powerful, dynamic, and artificial context that applies to each individual. Public education plays a role in the production of race as a social category through both implicit and explicit lessons and practices. Racial inequality has consistently been a troublesome and disheartening reality in the U.S. education system, and it deprives many children of equal opportunity (Lipman 2003; Nieto 2005; Putnam 2015).

Today, numerous states' public schools remain nearly as segregated as in earlier years, especially in urban communities where Black children are in the majority (Carter and Welner 2013; Pollock 2010). In many metropolitan areas, White children exclusively attend suburban public schools or private academies; by contrast, Black children primarily attend public schools in the city (Holme 2002; Murrell 2008). Continued school segregation leads to divided resources, low taxpayer support, and poor quality of education in these urban schools. Additionally, reformers often ignore racial segregation and accept it as inevitable. The consequences have been devastating for educational attainment and continuing economic disparities between racial groups.

In recent decades, education reforms have been sweeping the nation. Dramatically rising demands for accountability have given state and federal governments power to monitor fiscal inputs and determine the measurement of performance in public education (Ravitch 2010). Many states have adopted standardized tests, Common Core curricula, and teaching assessments in order to raise the quality and accountability of public education. Such drives for accountability often result in fiscal deficits and unequal opportunity for minority students (Ravitch 2010; Ravitch 2013; Sleeter 2007). The policies also neglect the actual problems of racial segregation (Lipman 2003). Educational resources are distributed unevenly on the basis of students' test scores, and without adequate support for education. Black students are hardly able to improve their academic achievement. Lower test scores lead to insufficient resources from the state government, and sometimes schools struggle with losing accreditation or are forced to close their doors due to students' poor testing performance (Lipman 2003; Pollock 2010; Ravitch 2010). As a consequence, racial inequality results in more complex problems in school environments. The White-Black achievement gap becomes wider. Black students in inner-city schools suffer unequal educational opportunities and are likely to encounter very low expectations for academic attainment (Carter and Welner 2013; MacLeod 2009; Murrell 2008; Putnam 2015; Sleeter 2007).

\section{SOCIOECONOMIC INEQUALITY IN PUBLIC EDUCATION}

Education is an investment that tends to increase 
opportunity for each individual's success and promote the common good of a country. Schooling also enables children to develop the cognizance of citizenship and decision-making skills, leading to the creation of a better society and boosting the nation's economy. However, today U.S. education plays a key role in the reproduction of inequality (Anyon 1981; MacLeod 2009). Students' performance is tied with multiple factors, such as school environment, teacher quality, class size, and educational support, all of which are affected by a school's socioeconomic status. In regard to educational access and school performance, socioeconomic capital matters in a number of ways. For instance, parents with higher socioeconomic status prefer the placement of their children into higher ability groups and social environments, which in turn increases more focus on raising the students' school engagement and enhancing their academic advantages (Lareau and Horvat 1999; Lee and Bowen 2006). Also, economic capital gives these parents more options because they have money available to offer their children with access to a variety of activities that are common in the high society and with educational assistance and private tutoring that are not receivable through public schools (Lareau 2000; Lareau 2003; Lareau and Horvat 1999; Lee and Bowen 2006). In other words, financial resources provide children with access to cultural capital and the ability to prepare for future competition.

In contrast, many children from impoverished families suffer numerous injustices (Lareau 2003; MacLeod 2009; Nieto and Bode 2008; Putnam 2015). They have a more difficult time attaining a high level of academic achievement because educational resources are inadequate. The schools in poor areas often receive less funding, so the schools have fewer resources available to improve academic achievement and provide quality education (Carter and Welner 2013; MacLeod 2009; Ravitch 2010; Ravitch 2013). Moreover, poor children and parents have fewer choices regarding the selection of a better community or school district. Therefore, the children from impoverished areas end up being victims under this arduous condition. The gaps between the performance of students from "good school districts" and those from "poor school districts" continue to accumulate. The goal of equal educational opportunity has never been achieved, and a nation with democracy has never been established.

In addition, the advocacy of individual choice in education leads to establishment of charter school systems, which creates difficult-to-overcome barriers and complex failures in democratic education (Ravitch 2010; Ravitch 2013). The ideas of individual choice and charter schools are a process toward educational inequalities. Charter schools are marketized and privatized public entities. The core concept behind the creation of charter schools is that they are associated with business interest groups. Many recent studies have indicated that charter schools worsen educational inequality and increase the gap among different socioeconomic populations because the under-the-table selection process and the lottery system of admission ruin fairness (Bartlett et al. 2002; Lipman 2003; Ravitch 2013). For example, many charter schools operate independently and autonomously, and they use a lottery process to decide enrollment by random selection. This leaves many children behind and deprives them of educational chances. Lottery winners receive tickets to the path of success; in contrast, lottery losers are doomed to settle for the problematic public education. Children's futures should not be determined on the basis of a simple gamble. Moreover, the growing competition for public funding between charter schools and public schools negatively affects poor districts with financial deficits (Bartlett et al. 2002; Ravitch 2010; Ravitch 2013). Businesses that become involved in public education generally tend to invest in potentially profitable areas, which are the high-income and majority-White districts. Also, many private education 
providers are unwilling to address the concerns of and to offer help to nurture low-income communities; instead, they believe it is faster and more profitable to put more effort and investment into wealthier communities and reach efficiency. This strongly skews unfairness against marginalized communities and discriminates based on race and class toward huge disparities in resources and the quality of education.

\section{EDUCATIONAL INEQUALITY AND FAILURE OF DEMOCRACY}

\section{The Collapse of Equal Opportunity}

The ultimate aim of democracy and education is to meet the need for freedom, liberty, and equality for all (Allen and Reich 2013; Barber 2001; Dewey 1916; Gutmann 1999; Gutmann 2001; Noddings 2013). A true democracy never advocates segregation and inequality with regard to race and class. On the contrary, many American children grow up without the skills and knowledge they need to thrive in the contemporary era due to relentless inequalities. Racial and socioeconomic discrimination has the ability to distinguish two types of citizens, privileged and unprivileged, which contradicts the core notion of democratic education.

Education is the major pillar upon which the future of the United States rests (Allen and Reich 2013; Dewey 1916; Gutmann 1999). It is constructed for the public good, and everyone should share in it equally. Schools should produce educated citizens who are capable of changing the destiny of a country and creating better opportunities for future generations. In order to help schools deliver high-quality education to every child, state governments and civic society must provide sufficient educational resources, equal public funding appropriations, and equal educational opportunities. With the aid of such support, schools will be able to help children develop their knowledge of democracy, prepare them for citizenship, and gain professional skills. However, the persistent failures of urban education and repeated efforts to change the problematic situations have shaped many of the educational policies and reforms over time. Unfortunately, the realities of racial segregation, educational inequalities, high dropout rates, low academic achievement, and insufficient resources have remained constant and have become complex challenges (Duncan and Murnane 2014; Lipman 2003; Ravitch 2010). These crises are deeply embedded in the intersection of racial oppression and socioeconomic inequality.

Public school funding comes from state and local sources, and nearly half of the money is derived from local taxes. This generates a large gap between wealthy and poor communities. The subject of poverty is often associated with race; hence, low-income minority students are the most affected by social and educational inequalities and face severe discrimination in their daily lives (Nieto 2005; Nieto and Bode 2008; Ravitch 2010; Ravitch 2013; Sleeter 2007). Take an in-depth instance, the current state of educational inequity in the Saint Louis Region, as represented by the Normandy School District which exemplifies the failure of urban education in regard to poverty and race. In the 2014 demographic profile of Normandy School District, nearly 98\% of the student population was Black, and $91.5 \%$ of the students received free and reduced lunch plans (Department of Elementary \& Secondary Education Missouri [DESE] 2014). Many city residents invest in the outcomes of students in high-income and White-dominated areas. Numerous educational resources and sufficient funding bolster the schools in these high-property districts. In contrast, the Normandy School District usually faces limited educational support which negatively impacts student performance. Loss of accreditation also forces the district to close schools, which takes away from students' educational opportunities. And the gap between low-income minority students and students of other racial and 
class groups becomes wider.

Since the early 1970s, the public has resisted the idea of racial integration and presently individual and parental choices in education increase the gap between racial and socioeconomic groups (Bartlett et al. 2002; Ravitch 2010; Ravitch 2013). Many low-income minority students have lost equal access for quality education. Citizens neglect the notion of public good and the goal of democracy (Barber 1993). Such ignorance and egotistical behavior among residents of urban areas destroy the progress of democratic education in inner-city public schools (Bartlett et al. 2002; Beal and Hendry 2012; Lipman 2003; Nieto 2005; Ravitch 2010; Ravitch 2013).

The fundamental concept of democracy aims to offer equal access to all members of society and to ensure that they are empowered to make a good life for themselves and establish the public good for the country. Quality education is a method to eliminate poverty and encourage the engine of shared prosperity for generations of Americans. When education improves the preparation and productivity of young members of the community, it increases the wealth of the country and leads many people to their American dreams. Nevertheless, the persistent and long-standing educational inequalities are an obstacle for the United States becoming a nation with true democracy and equal liberty. Thus, democracy becomes a superficial aspect and a beautiful bubble, and it is not realized in practice.

\section{The Collapse of Political Responsibility}

Hochschild and Scovronick (2003) stated, "Education also powerfully affects people's involvement with politics and their community, thereby creating another link between the nested structure of inequalities in schooling and the American dream" (Hochschild and Scovronick 2003: 24). Well-educated members of the community largely understand their obligation as participants in a democratic society, and they likely know current political facts and participate in political activities. The virtue of education in a democracy is that it tends to prepare children for citizenship and to foster in them the knowledge necessary for them to function in a civic society. But today in the United States, only some Americans fully exercise their political rights, and these are often citizens with high incomes, high socioeconomic statuses, and high levels of formal education. According to the American Political Science Association Taskforce (2005):

In 1990, nearly nine out of 10 individuals in families with incomes over $\$ 75,000$ reported voting in presidential elections, while only half of those in families with incomes under $\$ 15,000$ reported voting. Fifty-six percent (56\%) of those with incomes of at least $\$ 75,000$ reported participating in political campaign activities, compared with a mere 6\% among Americans with incomes under \$15,000. (American Political Science Association Taskforce 2005: 80-81)

The evidence indicates that there is a significant correlation between income status and the practice of citizenship. Americans with higher socioeconomic status usually enjoy not only higher educational achievement and salaries, but also have greater resources and skills to engage in politics and organizations. Education provides opportunities for Americans to acquire knowledge of democracy and to recognize their duty as members of a democratic society. Nevertheless, educational inequalities can lead to disparities in resources and skills between privileged and unprivileged people. The situation demolishes the goal of promoting democracy. The voices of U.S. citizens are heard unequally, and collective decisions respond much more to the privileged than to people of average means. The gap of inequality will increase. Instead of making progress, U.S. politics will continue to involve exclusion and unfairness, which strongly distorts the primary framework of democracy.

\section{The Collapse of Common Good}

Hochschild and Scovronick (2003) stated, “Achieving one's dream would not be possible past one generation, 
or for many even within the first generation, if the ideology of the American dream did not include prescriptions for pursuing collective goals" (Hochschild and Scovronick 2003: 13). Achieving the American dream and establishing a successful democratic nation require the transmission of knowledge, resources, and skills with great frequency (Allen and Reich 2013; Noddlings 2013). All members of the society should have an intellectually challenging education, including the necessary human and material resources. Schools must provide equal opportunity for all children and cultivate them to be effective contributors to their communities and should promote collaboration for the common good. Sadly, racial segregation and socioeconomic differentiation in schools push away the practices of equal opportunity and integration (Carter and Welner 2013; Duncan and Murnane 2014; Kozol 2006; Nieto 2005). Children from poor or minority families struggle with more problems related to socioeconomic constraints and racial discrimination. The current social, educational, and economic conditions are making wealthy people wealthier and poor people poorer and widening wage gaps between classes. Also, employment still largely depends on the levels of education and skills acquired (Lareau 2003; Lipman 2003). This causes many low-income people to be unable to meet their expenses even if they are working day and night. The power of this reality destroys the goal of U.S. democracy and the creation of common good.

Individual and parental choices in education increase the rate of segregation and reduce the spirit of integration and collaboration (Beal and Hendry 2012; Ravitch 2013). Upper- and middle-class parents opt to send their children to schools that match their social status or are dominated by their racial groups (Holme 2002; Lareau 2000; Lee and Bowen 2006). This makes it difficult for the government to prepare future generations for diversity and collaboration. Homogenous environments cannot help children to open themselves up and understand the notion of collaboration and the respect of individual differences (Holme 2002; Lareau 2003; Nieto and Bode 2008). Furthermore, choice allows the government to allocate educational resources unequally and encourages negative perceptions of selection to certain school districts. This leaves many low-income minority students behind and deprives them of educational opportunities.

The United States is a nation composed of diverse racial and ethnic populations. Everyone in the nation should be proud to reflect that through establishing equal opportunity and harmonious collaboration. Benjamin Franklin stated, "Younger people (should be) equipped to function as economically independent and politically sophisticated citizens" (as cited in L. Pangle and T. Pangle 2000: 29). Harmony, integration, and common interests are the major elements needed for a democratic society to flourish. The purpose of U.S. education is to prepare our children to reach common goals with adequate skills and knowledge, which assist them in developing a better future and nation (Allen and Reich 2013; Barber 2001; Goodland et al. 2004; Gutmann 1999; Gutmann 2001). However, racial segregation in schools, class discrimination, and growing educational inequality and inequity not only widen the gap between different racial and class groups, but also deepen the prejudiced attitudes and negative biases that work to further such situations in the first place. In essence, they threaten the goals of democracy, demolish collaborative opportunity, and ruin the aims of the common interest.

\section{CONCLUSIONS}

The core principles of U.S. education are supposed to include quality of educational opportunity and establishment of an equitable outcome. The principles should not advocate for a Race to the Top, a competition, or be a matter of individual choice with privileged sectors. U.S. education consistently needs 
to ensure the delivery of reliable, dependable, and equitable public services. The goal of the United States as a democratic society should be to provide an equal quality education to all children, so each of them has an equal chance to succeed in the world and promote the common good for the country.

Current educational reforms emphasize only high-stakes testing, test-based accountability, individual competition, and school choice, which all create a sense of crisis for racial segregation and class discrimination and lead to growing injustice in regard to educational opportunity. U.S. democracy is an ideal dream that offers possibilities for each citizen according to achievement and ability, free from racism, classism, and discrimination. Public education has been a primary mechanism for U.S. democracy, and it is also a reflection of society. Inferior education will eventually ruin our children, society, and nation. Nevertheless, education is the long-term solution for supporting social justice and fighting inequality. Children need to be equipped with adequate knowledge, critical thinking and judgment skills, and a sense of obligation and ethics. Both the government and the people share responsibility to give an equal chance and quality education to future generations, regardless of whether the child is from a wealthy or poor family or whether the child is White or Black. Education is a universal means of achieving other relative human rights, the protection of which is a core element of democracy. It can empower a country's economy and society. Preventing racial and class inequality in social and educational sectors is of utmost importance. True democracy always opposes educational inequality.

\section{References}

Allen, D. and R. Reich, eds. 2013. Education, Justice, and Democracy. Chicago, IL: The University of Chicago Press.

American Political Science Association Taskforce. 2005. “American Democracy and Inequality." Dissent 52(2):80-84.
Anyon, J. 1981. "Social Class and School Knowledge." Curriculum Inquiry 11(1):3-42.

Barber, B. 1993. "America Skips School: Why We Talk So Much About Education and Do So Little." Harper's Magazine, November (287), pp. 39-46.

—. 2001. "An Aristocracy of Everyone.” Pp. 11-22 in The Last Best Hope: A Democracy Reader, edited by S. J. Goodlad. San Francisco, CA: Jossey-Bass Publisher.

Bartlett, L., M. Frederick, T. Gulbrandsen, and Murillo. 2002. "The Marketization of Education: Public Schools for Private Ends." Anthropology \& Education Quarterly 33(1):1-25.

Beal, H. O. and P. M. Hendry. 2012. "The Ironies of School Choice: Empowering Parents and Reconceptualizing Public Education.” American Journal of Education 118(4):521-550.

Biesta, G. J. 2010. Good Education in an Age of Measurement: Ethics, Politics, Democracy. Interventions: Education, Philosophy, and Culture. Boulder, CO: Paradigm Publishers.

Carter, P. L. and K. G. Welner. 2013. Closing the Opportunity Gap: What America Must Do to Give Every Child an Even Chance. New York, NY: Oxford University Press.

Department of Elementary \& Secondary Education Missouri (DESE). 2014. District Demographic Data. Retrieved (http://mcds.dese.mo.gov/guidedinquiry/District\%20and\%2 0Building\%20Student\%20Indicators/District\%20Demograp hic\%20Data.aspx?rp:Districts=096109\&rp:SchoolYear=20 14\&rp:SchoolYear=2013\&rp:SchoolYear=2012\&rp:School Year=2011).

Dewey, J. 1916. Democracy and Education. An Introduction to the Philosophy of Education. New York, NY: Macmillan.

Duncan, G. J. and R. J. Murnane. 2014. Restoring Opportunity: The Crisis of Inequality and the Challenge for American Education. Cambridge, MA: Harvard Education Press.

Goodland, J. I., C. Mantle-Bromley, and S. J. Goodland. 2004. Education for Everyone: Agenda for Education in a Democracy. San Francisco, CA: Jossey-Bass Publisher.

Gutmann, A. 1999. Democratic Education. Princeton, NY: Princeton University Press.

—. 2001. "Democratic Education in Difficult Times." Pp. 216-232 in The Last Best Hope: A Democracy Reader, edited by S. J. Goodlad. San Francisco, CA: Jossey-Bass Publisher.

Hochschild, J. L. 1996. Facing Up to the American Dream. Princeton, NJ: Princeton University Press.

Hochschild, J. L. and N. Scovronick. 2003. The American Dream and the Public Schools. New York, NY: Oxford University Press, Inc.

Holme, J. J. 2002. "Buying Homes, Buying Schools: School Choice and the Social Construction of School Quality.” Harvard Educational Review 72(2):177-205. 
Kozol, J. 1991. Savage Inequalities: Children in America's Schools. New York, NY: Crown Publishing Group.

- 2006. The Shame of the Nation: The Restoration of Apartheid Schooling in America. New York, NY: Crown Publishing Group.

- 2013. Fire in the Ashes: Twenty-Five Years Among the Poorest Children in America. New York, NY: Crown Publishing Group.

Labaree, D. F. 1997. "Public Goods, Private Goods: The American Struggle Over Educational Goals.” American Educational Research Journal 34(1):39-81.

Lareau, A. 2000. Home Advantage: Social Class and Parental Intervention in Elementary Education. Lanham, MD: Rowman \& Littlefield Publishers, Inc.

—_ eds. 2003. Unequal Childhoods: Class, Race, and Family Life. Berkeley and Los Angeles, CA: University of California Press.

Lareau, A. and E. M. Horvat. 1999. "Moments of Social Inclusion and Exclusion: Race, Class, and Cultural Capital in Family-School Relationships.” Sociology of Education 72(1):37-53.

Lee, J. S. and N. K. Bowen. 2006. "Parent Involvement, Cultural Capital, and the Achievement Gap Among Elementary School Children.” American Educational Research Journal 43(2):193-218.

Lipman, P. 2003. High Stakes Education: Inequality, Globalization, and Urban Schools Reform. New York, NY: Routledge.

Love, D. A. 2011. "Racial Inequality in Education Hurts America’s Global Competitiveness.” The Progressive Since 1909. Retrieved (http://progressive.org/education_racial_ inequality.html).

MacLeod, J. 2009. Ain't No Makin' It: Aspirations \& Attainment in a Low-Income Neighborhood. Boulder, CO: Westview Press.

Murrell, P. C. 2008. Race, Culture, and Schooling. Identities of Achievement in Multicultural Urban Schools. New York, NY: Routledge.

National Center for Education Statistics (NCES). 2013. Public
School Graduates and Dropouts From the Common Core of Data: School Year 2009-2010. Retrieved (http://nces. ed.gov/pubsearch/pubsinfo.asp?pubid=2013309rev).

Nieto, S. 2005. "Public Education in the Twentieth Century and Beyond: High Hopes, Broken Promises, and an Uncertain Future." Harvard Educational Review 75(1):43-64.

Nieto, S. and P. Bode. 2008. Affirming Diversity: The Sociopolitical Context of Multicultural Education. New York: Allyn \& Bacon.

Noddings, N. 2013. Education and Democracy in the 21st Century. New York, NY: Teachers College Press.

Pangle, L. S. and T. L. Pangle. 2000. "What the American Founders Have to Teach Us About Schooling for Democratic Citizenship.” Pp. 21-46 in Rediscovering the Democratic Purposes of Education, edited by L. M. McDonnell, P. M. Timpane, and R. Benjamin. Lawrence, KS: University Press of Kansas.

Pollock, M. 2010. Because of Race: How American Debate Harm and Opportunity in Our Schools. Princeton, NJ: Princeton University Press.

Putnam, R. D. 2015. Our Kids: The American Dream in Crisis. New York, NY: Simon \& Schuster.

Ravitch, D. 2010. The Death and Life of the Great American School System: How Testing and Choice Are Undermining Education. New York, NY: Basic Books.

- 2013. Reign of Error: The Hoax of the Privatization Movement and the Danger to America's Public Schools. New York, NY: Alfred A. Knopf.

Sleeter, C. E. 2007. Facing Accountability in Education: Democracy and Equity at Risk. New York, NY: Teachers College Press.

\section{Bio}

Amy Yun-Ping Chen, Ph.D. candidate, Saint Louis University, USA; research fields: social justice education, multicultural education, teacher education, social inequity, and curriculum development. 